\title{
Back to the Nature: Effects of Non-Pharmacological Modalities in Mechanically Ventilated Neonates
}

Mossad AbdelHak Shaban Mohamed ${ }^{1}$, Taufiq Hidayat ${ }^{1}$, Asrar Abu Bakar ${ }^{1}$, Azamin Anuar $^{1}$, Mohd Fit'ri Akmal Mohd Sofee'2, Abdelbaset Taher Abdelhalim ${ }^{3}$

${ }^{1}$ Department of Paediatrics, Kulliyyah of Medicine, International Islamic University Malaysia

2Department of Pharmacology, Faculty of Medicine, Alazhar University, Egypt ${ }^{3}$ WIDAD University College Kuantan Malaysia.

Introduction: Neonates refers to the first 28 days of life, they are vulnerable to physiological changes. About $15 \%$ of neonates get admitted to NICU and a significant number of them end up in ventilation. This study assessed the beneficial role of nonpharmacological modalities on recovery with a better outcome of ventilated babies in NICU. Material and Methods: The study is a quantitative cross-sectional study for 9 months of NICU at IIUMMC. The study will include top conditions warranting neonatal intensive care unit (NICU) admissions and ventilation as preterm, respiratory distress, neonatal sepsis, HIE, and others. They are divided into two (2) groups; the first group will keep the standard practice and assigned as a control group. The second group will afford all or most of a package of non-pharmacological and sensory stimuli like a kangaroo, feeding, non-nutritive sucking, swaddling, skinto-skin contact, sensory saturation, soft massage, away irritant odour, Normal visual experience during daytime and dime light at night-time. decrease sound pollution, and voice stimulation assessing soft music or recitation of the Qur'an according to family preference. We will assess stabilizing vital signs, behavioural assessment, extubating timing, Short term outcome. Results: Adding non-pharmacological modalities could reduce the dose requirements for sedation and analgesics and has a positive effect on the neurodevelopmental outcome. Conclusion: nonpharmacological strategies besides other modalities improved short-term outcomes and the recovery of ventilated babies. The importance of coming back to nature, the effect of special senses and sensory stimulation on neonatal recovery, and ease extubation. 